\title{
Fertilización in vitro (FIV) de ovocitos obtenidos en ovejas mediante la técnica de recolección laparoscópica de óvulos
}

\author{
In vitro fertilization (IVF) of oocytes obtained from sheep using the laparoscopic ovum \\ pick up technique
}

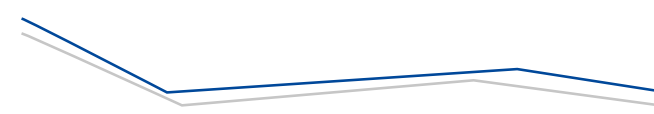

Julio Ramón-Ugalde*®, Deneb Cervera-Paúl *, Álvaro DomínguezRebolledo**, Juan Baeza-Rodríguez**, Luis Pinzón-López*, Roberto Zamora-Bustillos*

Ramón-Ugalde, J., Cervera-Paúl, D., Domínguez-Rebolledo, A., Baeza-Rodríguez, J., Pinzón-López, L., \& Zamora-Bustillos, R. (2020). Fertilización in vitro (FIV) de ovocitos obtenidos en ovejas mediante la técnica de recolección laparoscópica de óvulos. Investigación y Ciencia de la Universidad Autónoma de Aguascalientes, 28(81), 15-23.

RESUMEN

Con el objetivo de poner a punto la técnica de recolección laparoscópica de óvulos (LOPU) y desarrollar un protocolo de fertilización in vitro (FIV) dos grupos de ovejas; el primero, Gl, con 3 prepúberes y G2, con 3 adultas, fueron sincronizadas (esponjas vaginales 14 días) y superovuladas (FSHP), iniciando $60 \mathrm{~h}$ antes de cada LOPU (tres sesiones). La aspiración folicular laparoscópica se realizó a las $12 \mathrm{~h}$ de la última dosis de FSHp. La tasa de recuperación global de los ovocitos en tres sesiones de LOPU en el G2 y G1, fue de $41.0 \pm 2.5$ y $24.0 \pm 2.4 \% \mathrm{EEM}$, respectivamente, presentando diferencias $(P<0.05)$ a favor del G2. El cultivo in vitro de los ovocitos a las $48 \mathrm{~h}$ presenta una diferencia $(P<0.05)$ a favor del $G 1(9.7 \%)$ respecto a

Palabras clave: ovinos; ovocitos; embriones; biotécnicas; maduración; laparoscopía.

Keywords: sheep; oocytes; embryos; biotech; maturation; laparoscopy.

Recibido: 27 de noviembre de 2019, Aceptado: 20 de octubre de 2020

* Tecnológico Nacional de México campus Conkal. Antigua carretera Mérida-Motul km 16.3, Conkal, C. P. 97345, Yucatán, México. Correo electrónico: julio.ramon@itconkal.edu.mx; edencepa83@hotmail. com; wichorama@gmail.com; roberto.zamora@itconkal.edu.mx ORCID: http://orcid.org/0000-0002-9312-8438; http://orcid.org/00000002-4508-9462; http://orcid.org/0000-0002-8405-3948; http://orcid. org/0000-0002-4502-1492

** Instituto Nacional de Investigaciones Forestales, Agrícolas y Pecuarias campo experimental Mocochá. Antigua carretera Mérida-Motul km 24.5, Mocochá, C. P. 97454, Yucatán, México. Correo electrónico: alvaroedr@gmail.com; baeza.juanjose@inifap.gob.mx ORCID: http:// orcid.org/0000-0002-1444-3844; http://orcid.org/0000-0001-9339-9695

Autor para correspondencia
G2 (0.0). En conclusión, se logró sistematizar la técnica de LOPU e implementar un protocolo de fertilización in vitro a partir de ovocitos recuperados y fertilizados.

\section{ABSTRACI}

In order to fine-tune the laparoscopic ovum pick up (LOPU) technique and develop an in vitro fertilization (IVF) protocol, two groups of sheep were synchronized (vaginal sponges 14 days) and superovulated (FSHp), beginning 60 hours before each LOPU (3 sessions). Laparoscopic follicular aspiration was performed 12 hours after the last dose of FSHp. The overall recovery rate of oocytes in three LOPU sessions in G2 and G1 was $41.0 \pm 2.5$ and $24.0 \pm 2.4 \%$ SEM, respectively, presenting differences $(P<0.05)$ in favor of $G 2$. In vitro oocyte culture at 48 hours showed a difference $(P<0.05)$ in favor of $G 1 \quad(9.7 \%)$ with respect to $G 2$ (0.0). In conclusion, it was possible to systematize the LOPU technique and implement an in vitro fertilization protocol from recovered and fertilized oocytes.

\section{INTRODUCCIÓN}

Desde el primer registro comercial de inseminación artificial en 1908 (Thibier, 1990) la biotecnología reproductiva en animales domésticos ha tenido avances importantes, como la clonación y creación de animales transgénicos. Los pequeños rumiantes ofrecen un buen modelo para el desarrollo de estas tecnologías, de ahí que la producción in vitro de embriones constituye, junto con el sexado, la tercera generación biotecnológica de la reproducción. Las investigaciones sobre fertilización in vitro (FIV) se iniciaron al final 
de la década de 1950, cuando se produjo el nacimiento de conejos por esta técnica (Chang, 1959). Aunque la FIV progresó rápidamente en mamíferos de laboratorio su desarrollo fue más lento en las especies domésticas, ya que el nacimiento del primer becerro mediante FIV se logró en 1982 (Brackett et al., 1982). Estos años de retraso fueron consecuencia de problemas metodológicos, ya que las condiciones requeridas para la capacitación espermática, la MIV (maduración in vitro) de ovocitos y el desarrollo embrionario preimplantación difieren entre especies de embriones.

Para la aplicación de esta y otras técnicas de reproducción asistida ha sido necesaria la obtención de ovocitos de hembras vivas y postmortem, así como implementar la producción de embriones mediante la FIV. Estos procedimientos resultan cada vez más importantes para el ganado ovino, ya que ofrecen oportunidades para investigación, así como para su aplicación en programas de cría de ovinos. Sin embargo, el porcentaje de éxito es aún muy bajo $(<40 \%)$ debido a factores intrínsecos y extrínsecos del ovocito, tales como la raza materna y el origen del semen para llevar a cabo la FIV; por tanto, su desarrollo en Medicina Veterinaria y especialmente en pequeños rumiantes resulta un área con potencial importante (Tibary, Anouassi, \& Khatir, 2005). Por otro lado, sus limitaciones son también tecnológicas y se ven relacionadas con las interacciones entre el embrión y su ambiente durante el cultivo, las cuales a su vez guardan estrecha relación con el ambiente uterino de los embriones obtenidos in vivo, tales como la nutrición, el estado corporal y la sanidad (Palma, 2008). Resulta de gran valor la aplicación y estandarización de estas técnicas bajo la hipótesis de que el desarrollo de los ovocitos fertilizados in vitro está influenciado por la edad reproductiva, de tal modo que este trabajo tuvo como objetivo la estandarización de la técnica de LOPU y el desarrollo de un protocolo de fertilización in vitro.

\section{MATERIALES Y MÉTODOS}

El presente trabajo se realizó en primavera, las actividades se llevaron a cabo en el laboratorio de Biotecnología Reproductiva y Genética Molecular del Instituto Tecnológico de Conkal, Yucatán, localizado en la región centro norte del estado comprendido entre los paralelos $21^{\circ} 02^{\prime}$ y $21^{\circ} 08^{\prime}$ latitud norte y los meridianos $89^{\circ} 29^{\prime}$ y $89^{\circ} 35^{\prime}$ longitud oeste; posee una altura promedio de $8 \mathrm{~m} \mathrm{~s}$. n. m., el clima cálido es subhúmedo con lluvias regulares en verano (mayo-julio). Temperatura media anual de $26.6^{\circ} \mathrm{C}$ y precipitación pluvial media anual de 469 $\mathrm{mm}$ y una humedad relativa promedio anual: marzo $66 \%$ - diciembre 89\% (INAFED \& Gobierno del estado de Yucatán, 2005). Todos los procedimientos con animales se llevaron a cabo dentro de las directrices de las técnicas oficiales de cuidado animal y salud en México (NOM-051-ZOOO-1995).

\section{Animales, dietas y manejo}

Se utilizaron dos grupos de ovejas de pelo, las cuales se distribuyeron según su edad reproductiva: tres hembras prepúberes (G1) y tres hembras adultas (G2). El manejo nutricional para ambos grupos fue de $5 \mathrm{~h}$ de pastoreo en estrella de África (Cynodon nlenfuensis) y un suplemento comercial con $14 \%$ de

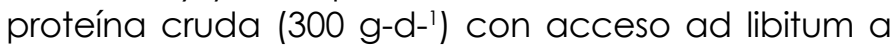
agua y sales minerales.

\section{Tratamiento de sincronización y superovulación}

Todos los animales (seis ovejas) fueron sincronizados mediante la inserción de esponjas vaginales impregnadas con $20 \mathrm{mg}$ de acetato de fluorogestona micronizada (Chronogest; Intervet ${ }^{\circledR}$ ) durante 14 días (primer bloque), posteriormente cada siete días se sustituyó la esponja por una nueva en tres periodos sucesivos. El tratamiento de estímulo superovulatorio se realizó mediante la aplicación de 5 dosis decrecientes de FSHp (Folltropin®) a intervalos de $12 \mathrm{~h}(12.5 \mathrm{mg}$ en $0.62 \mathrm{ml}, 12.5 \mathrm{mg}$ en $0.62 \mathrm{ml}, 9.3 \mathrm{mg}$ en $0.46 \mathrm{ml}, 9.3 \mathrm{mg}$ en $0.46 \mathrm{ml}$ y $6.25 \mathrm{mg}$ en $0.31 \mathrm{ml}$ ) iniciando $60 \mathrm{~h}$ antes de cada LOPU y renovación de esponja (cada semana después de los primeros 14 días). Al primer bloque se le aplicó una dosis única de $2 \mathrm{ml}$ de $\mathrm{PGF}_{2} \alpha$ (Lutalyse®) coincidiendo con la primera aplicación de FSHp. A las $12 \mathrm{~h}$ de la última aplicación de FSHp se realizó la aspiración folicular por laparoscopía (LOPU).

\section{Sementales}

Se utilizaron de manera aleatoria cuatro machos de diferente raza (Dorper, Katahdin, Black Belly y Pelibuey) de fertilidad probada, de los cuales se obtuvo un eyaculado semanal, el cual fue empleado para las pruebas de fertilización in vitro.

\section{Obtención de suero de oveja en celo (SOC)}

Se utilizaron 10 ovejas para la obtención de suero de oveja en celo en dos etapas (cinco en cada 
experimento). Los ejemplares fueron sincronizados e inducidos al estro a través de la aplicación de una esponja vaginal (día 0) impregnada con $20 \mathrm{mg}$ de acetato de fluorogestona micronizada (Chronogest ${ }^{\circledR}$, Intervet), remplazada al día 7 de la aplicación y en coincidencia con una dosis de $3 \mathrm{ml}$ de $\mathrm{PGF}_{2} \alpha$ (Lutalyse $\AA$ ). En ambos grupos después de haber sido detectado el celo se procedió a la obtención de una muestra de sangre en tubos sin heparina. Las muestras fueron centrifugadas a 2500 r. p. m. durante cinco minutos, posteriormente el suero (sobrenadante) fue retirado y filtrado en un filtro de $0.22 \mu \mathrm{m}$ (Milliporeß). El suero obtenido fue inactivado en un baño María a $56^{\circ} \mathrm{C}$ por $30 \mathrm{~min}$ y finalmente alícuotas de $1 \mathrm{ml}$ fueron almacenadas a $-20{ }^{\circ} \mathrm{C}$ (Khodaei, Shahneh, Daliri, Kohram, \& Gharagozlou, 2008).

\section{Obtención de fluido folicular (FF)}

Se utilizó el mismo grupo de ovejas, del cual fue obtenido el SOC, inducido y sincronizado mediante CIDR. Al día 4 de la aplicación del dispositivo se les aplicó $1000 \mathrm{UI}$ de eCG (Folligon®) a cada una y el día 7 se llevó a cabo la aspiración folicular a través de una jeringa sin émbolo. Se aspiraron folículos $>3$ $\mathrm{mm}$, al fluido obtenido se le añadió heparina a una concentración final de $2 \mu \mathrm{l}-\mathrm{ml}^{-1}$ y posteriormente se centrifugó a 2,500 r. p. m. durante $2 \mathrm{~min}$, el sobrenadante obtenido fue recogido para hacer alícuotas de $1 \mathrm{ml}$ que se almacenaron a $-20{ }^{\circ} \mathrm{C}$ (Hammami, 2008).

\section{Dinámica de recolección laparoscópica de óvulos (LOPU)}

Todos los animales se mantuvieron a dieta sólida y líquida durante $24 \mathrm{~h}$ previas a la LOPU. Para llevar a cabo la aspiración folicular fueron sedados con una mezcla de $10 \mathrm{ml}$ de ketamina $100 \AA(10 \mathrm{mg} / \mathrm{ml})$ con $1.25 \mathrm{ml}$ de clorhidrato de xilacinaß a $2 \%$ (23.3 $\mathrm{mg} / \mathrm{ml}$ ) aplicado por vía endovenosa a razón de $1.1 \mathrm{ml}$ de la mezcla $(11 \mathrm{mg}$ de ketamina $+2.91 \mathrm{mg}$ de clorhidrato de xilacina) por cada $50 \mathrm{~kg}$ de peso vivo (Ramón-Ugalde, Folch, Cocero, Piña-Aguilar, \& Alabart, 2008). Se realizaron tres orificios con un trocar en la parte caudal del abdomen. El izquierdo fue empleado para introducir el endoscopio. En el central se fijó una sonda provista con una aguja de $21 \mathrm{G}$ y longitud de $1 \mathrm{~cm}$ para aspirar los folículos mayores de $2 \mathrm{~mm}$, la parte externa de la sonda se conectó a un tubo que contenía medio de aspiración (previamente atemperado y equilibrado) y el otro extremo se conectó a una bomba de aspiración (Meditec $\AA$ ) regulada a una presión de 20 a $40 \mathrm{ml}$ por minuto (Palma, 2008). En el orificio derecho se colocó una pinza que permitió inmovilizar y fijar el ovario al momento de la aspiración. Finalmente, después de la intervención se irrigó el ovario con suero y heparina para reducir la formación de adherencias.

\section{Maduración in vitro}

Medio de maduración in vitro: TCM199 + FSHp (50 mg$\left.\mathrm{ml}^{-1}\right)+10 \%$ fluido folicular (FF). El medio de maduración fue preparado el mismo día que se empleó, se suplementó con FSHp (Folltropin $\circledast$ ) y $10 \%$ de FF y se procedió a esterilizar el medio con filtros de $0.22 \mu \mathrm{m}$ (Millipore®) de baja retención de proteínas dentro de una campana de flujo laminar vertical. Finalmente se equilibró el medio en una incubadora (Binder ${ }^{\circledR}$, mod CB-53) de atmósfera controlada a $5 \%$ de $\mathrm{CO}_{2}$ en aire, $38.5^{\circ} \mathrm{C}$ y humedad máxima, por lo menos $2 \mathrm{~h}$ antes de su uso. Los ovocitos provenientes del área de cirugía fueron aspirados con TCM199 + HEPES, $0.2 \%$ de BSA (bovine serum albumin) y heparina sódica y vertidos dentro de una placa Petri cuadriculada y aclarados con TCM199 + HEPES.

La recuperación de los ovocitos se llevó a cabo en el laboratorio in vitro con un microscopio estereoscópico. Los ovocitos recuperados por raza fueron depositados en una placa Petri con $2 \mathrm{ml}$ de medio, los cuales recibieron un lavado en los cuatro pozos de la placa en un medio que contenía TCM199 sin HEPES. Los ovocitos recuperados fueron clasificados según su calidad en categorías 1, 2 y 3 por la apariencia del citoplasma y la cantidad de capas de células de la granulosa; sin embargo, debido al bajo número y calidad de los ovocitos obtenidos todos se maduraron durante $24 \mathrm{~h}$. Se hicieron dos grupos: uno de ovocitos de hembras adultas y otro de hembras prepúberes.

\section{Fertilización in vitro}

Una vez concluidas las $24 \mathrm{~h}$ de maduración in vitro se procedió a denudar los ovocitos de las células de la granulosa con una pipeta a flujo constante y presión de $180 \mu \mathrm{l}$. Los ovocitos denudados recibieron dos lavados previos a ser colocados en medio fluido oviductal sintético (SOF) (stock salt, stock $\mathrm{NaHCO}_{3^{\prime}}$ stock $\mathrm{CaCl}_{2}, \mathrm{Na}$ piruvato, MEM aminoácidos no esenciales, BME aminoácidos esenciales, glutamina y gentamicina). Este medio se preparó el mismo día 
a utilizar, se esterilizó con filtros de $0.22 \mu \mathrm{m}$ y baja retención de proteínas (Millipore ${ }^{\circledR}$ ) dentro de una campana de flujo laminar vertical. Finalmente, el medio se equilibró dentro de una incubadora de atmósfera controlada con $5 \%$ de $\mathrm{CO}_{2}$ en aire, 38.5 ${ }^{\circ} \mathrm{C}$ y humedad máxima por lo menos $2 \mathrm{~h}$ antes de su uso. Después de los lavados, los ovocitos denudados fueron colocados en SOF y finalmente fertilizados a una concentración final de $1 \times 10^{6}$ espermatozoides.

\section{Colecta seminal}

El semen fue colectado a través de vagina artificial. El eyaculado de los machos se almacenó a temperatura ambiente y completa oscuridad por 2 $\mathrm{h}$, posteriormente se enrasó con medio SOF (v:v), el cual fue adicionado con BSA a $4 \%$ y centrifugado a 2,500 r. p. m. El sobrenadante fue retirado, con lo que se obtuvo una pequeña porción del material aglomerado donde se encontraban los espermatozoides. Para obtener la concentración del material aglomerado se empleó una cámara de Neubaver en un microscopio de contraste de fases. La muestra de semen fue colectada de machos de fertilidad probada escogidos aleatoriamente, se obtuvo un eyaculado por macho y por semana, cubriendo las cuatro sesiones.

\section{Cultivo in vitro}

Cumplidas las $24 \mathrm{~h}$ de incubación de los gametos fueron retirados de la estufa de cultivo para ser colocados dentro de la masa de espermatozoides. Cabe mencionar que debido al espesor del semen algunos ovocitos no se encontraron. Su búsqueda se llevó a cabo aplicando corrientes constantes del medio con una pipeta a una presión de $150 \mu$ l. Los ovocitos recuperados se colocaron en una placa con medio (SOF + BSA 8\%) previamente equilibrado con la finalidad de limpiarlos de los espermatozoides que se encontraban adheridos a lazona pelúcida. Los posibles cigotos obtenidos a las $24 \mathrm{~h}$ después de la FIV fueron observados con un microscopio estereoscópico para determinar el número de fertilizados y su división a dos o más células. Los presuntos cigotos se cultivaron en una placa de cuatro pozos con medio SOF + BSA $8 \%+$ $10 \%$ FCS (fetal calf serum) y se recubrieron con aceite mineral para evitar la evaporación y cambio de $\mathrm{pH}$ del medio. A las $48 \mathrm{~h}$ de la FIV se valoró nuevamente el número de embriones divididos y el número de células, se mantuvieron durante siete días en cultivo para determinar si continuaba la división embrionaria hasta blastocisto.

\section{Diseño experimental}

Se empleó un diseño completamente al azar para ponderar variables dependientes como se describe a continuación.

1. Para la estandarización de la técnica de aspiración folicular por laparoscopía se llevó a cabo mediante un análisis de prueba de hipótesis con las variables correspondientes a las ovejas: tasa de folículos aspirados y ovocitos recuperados.

2. Para medir la variable tasa de recuperación se utilizaron para el análisis las siguientes variables independientes: efecto de la edad reproductiva y sesión de LOPU.

El modelo estadístico general utilizado para medir los efectos de los factores analizados fue el siguiente:

$$
y_{i j k}=\mu+E R_{i}+L_{j}+E L_{(i j)}+e_{i j k}
$$

El modelo se analizó con el procedimiento GLM del programa estadístico SAS 9.2. La ponderación de los datos se realizó mediante análisis de varianza y se evaluaron el modelo y sus efectos. La comparación de las medias de cuadrados mínimos se realizó a través de la diferencia mínima significativa al nivel de $P<0.05$.

3. Para evaluar el efecto de la edad reproductiva (adultas-prepúberes) sobre la tasa de división a $48 \mathrm{~h}$ se utilizó la prueba de t de Student.

Para la estandarización de la técnica laparoscopic ovum pick up (LOPU) se realizó una prueba de hipótesis (tabla 1) para poder determinar la media mínima necesaria, la cual resultó $26.0 \pm 3.0 \%$ de ovocitos recuperados en ovejas de diferente edad reproductiva (adultas y prepúberes), con lo que se determinó si la técnica empleada estaba estandarizada. En la LOPU 2 los resultados se encuentran ligeramente por debajo con un $25.0 \%$ de recuperación; sin embargo, los resultados de la LOPU 1 y 3 presentan 30.0 y $36.3 \%$ de recuperación 
de ovocitos, respectivamente, lo cual indica que se encuentran dentro del rango de respuesta a la hipótesis realizada (tabla 2). La tasa de recuperación global para adultas y prepúberes fue de $24.0 \pm 2.4 \%$ y $41.0 \pm 2.5 \%$, respectivamente. En las tres sesiones se aspiraron un total de 198 folículos, de los cuales fueron recuperados 59 ovocitos. De acuerdo con la edad reproductiva, 86 folículos fueron aspirados y 32 ovocitos recuperados en las ovejas adultas, mientras en las prepúberes 112 folículos fueron aspirados y 27 ovocitos recuperados.

La tabla 3 muestra la tasa de recuperación global de los ovocitos en las tres sesiones de LOPU en adultas y prepúberes con $41.0 \pm 2.5$ y $24.0 \pm 2.4 \%$,

Tabla 1

Estandarización de la técnica LOPU en ovejas prepúberes y adultas

\begin{tabular}{cccc}
\hline No. & Media (\%) & Error Estándar (\%) & Prob > \\
\hline 17 & 26.0 & 3.0 & 0.05 \\
\hline
\end{tabular}

Nota: Elaboración propia.

Tabla 2

Folículos aspirados aplicando la técnica LOPU sobre la tasa de eficiencia en la recuperación de ovocitos

\begin{tabular}{lccccccccccc}
\hline Edad Reproductiva & \multicolumn{3}{c}{ LOPU 1 } & & LOPU 2 & & \multicolumn{2}{c}{ LOPU 3 } \\
\hline & No. & AT & RT & No. & AT & RT & No. & AT & RT \\
\cline { 2 - 10 } Prepúber & 3 & 35 & 10 & 3 & 40 & 8 & 3 & 37 & 9 \\
Adulta & 3 & 35 & 11 & 3 & 33 & 10 & 2 & 18 & 11 \\
TOTAL & 6 & 70 & 21 & 6 & 73 & 18 & 5 & 55 & 20 \\
\hline
\end{tabular}

Nota: No.= Número de observaciones, AT= Foliculos aspirados totales, RT= Ovocitos recuperados totales.

Elaboración propia.

respectivamente, con diferencias $(P<0.05)$ a favor del grupo de las adultas. Para los resultados analizados individualmente en las sesiones de LOPU las tasas de recuperación de ovocitos en la sesión 1 y 2 no presentaron diferencias significativas, fueron ligeramente mayores para las adultas; sin embargo, en la LOPU 3 la tasa de recuperación para estas (61.0 $\pm 5.0 \%$ ovocitos recuperados) fue mayor $(P<0.05)$ que la observada en las prepúberes (25.0 4. \pm 0\%).

La tasa de fertilización para las tres sesiones de LOPU se muestra en la tabla 4; la relación entre el número de ovocitos fertilizados y el total de ovocitos cultivados 
fue de 9.0\%. Estos valores corresponden exclusivamente a hembras prepúberes, ya que el valor de fertilidad para las adultas fue de $0.0 \%$.

Tabla 3

Efecto de la edad reproductiva (prepúberes G1 - adultas G2) sobre la tasa de recuperación de ovocitos en las tres sesiones de LOPU

\begin{tabular}{llllll}
\hline T & N & LOPU 1 (\%) & LOPU 2 (\%) & LOPU3 (\%) & Media Global (\%) \\
\hline G1 & 9 & $28.0 \pm 4.0^{\mathrm{b}}$ & $21.0 \pm 4.0^{\mathrm{b}}$ & $25.0 \pm 4.0^{\mathrm{b}}$ & $24.0 \pm 2.4^{\mathrm{b}}$ \\
G2 & 8 & $32.0 \pm 4.0^{\mathrm{b}}$ & $32.0 \pm 4.0^{\mathrm{b}}$ & $61.0 \pm 5.0^{\mathrm{a}^{*}}$ & $41.0 \pm 2.5^{\mathrm{a}^{*}}$ \\
\hline
\end{tabular}

Nota: *Literales diferentes en la misma columna indican diferencia significativa a $P<0.05$, Tukey.

Elaboración propia.

Tabla 4

Tasa de fertilidad en las diferentes sesiones de LOPU en ovejas prepúberes

\begin{tabular}{lccc}
\hline & TOC & TOF & TASA DE FERTILIDAD (\%) \\
\hline LOPU 1 & 21 & 0 & 0.0 \\
LOPU 2 & 17 & 2 & 11.7 \\
LOPU 3 & 17 & 3 & 17.6 \\
TOTAL & 55 & 5 & 9.7 \\
\hline
\end{tabular}

Nota: $*$ TOC $=$ Total de ovocitos cultivados, TOF= Total de ovocitos fertilizados.

Elaboración propia.

Los datos globales de ovocitos obtenidos en ovejas adultas y prepúberes arrojan 0.0 y $9.7 \%$, respectivamente, para los datos de fertilidad obtenida durante las tres sesiones de LOPU. LOS resultados productivos de fertilidad según la edad reproductiva de los ovocitos provenientes de ovejas prepúberes fueron los que se fertilizaron en las sesiones de LOPU 2 y 3 en contraste con el de las adultas, que fue 0.
Después de llevarse a cabo el cultivo in vitro de los ovocitos, a estos se les dio seguimiento para determinar la tasa de división obtenida (figura 1).

En cuanto a los resultados observados a las 48 h se presenta una diferencia $(P<0.05)$ a favor de las ovejas prepúberes con $9.7 \%$ y adultas con $0.0 \%$. 


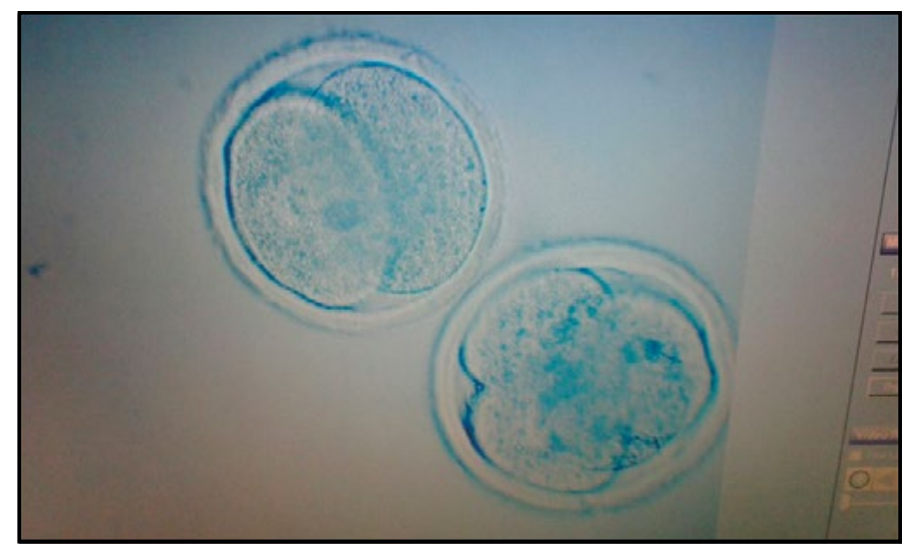

Figura 1. División celular de ovocitos cultivados a las $48 \mathrm{~h}$ posfertilización.

Fotografia tomada por Julio Ramón-Ugalde.

Los resultados en relación con el número de folículos aspirados indican que existe una mejor respuesta folicular en ovejas prepúberes (112) que en adultas (86). Según Baldassarre (2007) no se conoce el motivo de esta respuesta folicular en prepúberes. En adultas se ha observado una mayor atresia folicular en primavera que en otoño (Juárez-Pérez et al., 2018). Los resultados obtenidos en el presente trabajo coinciden con los de Koeman, Keefer, Baldassarre y Downey (2003) en cabras prepúberes (3-5 meses) y adultas (>1 año) y en época no reproductiva (junioseptiembre), los cuales obtuvieron $39 \pm 4.5 \%$ y $19 \pm$ $1.4 \%$, respectivamente; sin embargo, aun en cabras prepúberes existen diferencias entre rangos de edades. Baldassarre et al. (2004) mediante la técnica de LOPU obtuvieron $28.5 \pm 5$ folículos en cabras $>180$ días de edad, de las cuales obtuvieron $25.8 \pm 6$ en la recuperación, en cabras $<100$ días de edad se obtuvieron $57.0 \pm 16.0$ folículos aspirados y $41.0 \pm 9$ en la recuperación.

En un estudio realizado por Shirazi, ShamsEsfandabadi y Hosseini (2005) se realizó la recuperación de ovocitos de ovejas adultas y prepúberes con ovarios de matadero y en época no reproductiva por medio de dos técnicas (aspiración y corte). Los resultados para la recuperación fueron 8.1 y 6.3 ovocitos; 3.7 y 4 ovocitos para adultas y prepúberes, respectivamente, diferencias $(P<0.001)$ a favor de las ovejas adultas.

En cabras adultas y en plena estación sexual
Romaguera et al. (2007) obtuvo 248 ovocitos aspirados mediante la técnica de LOPU, de los cuales se recuperaron 138, con $57 \%$ de ovocitos recuperados; sin embargo, cabe señalar que la eficacia de la recuperación según la bibliografía va desde 33.6\% (Alberio, Olivera, Roche, Alabart, \& Folch, 2002) hasta $90 \%$ (Pierson et al., 2004). Las diferencias encontradas en el presente trabajo podrían ser atribuidas al diámetro de los folículos de donde fueron aspirados, lo cual coincide con el trabajo de Cox \& Alfaro (2007) en ovejas y cabras adultas, quienes obtuvieron un porcentaje de ovocitos recuperados significativamente inferior en los folículos más pequeños. Martino, Mogas, Palomo y Paramio (1994) establecen que en folículos de cabras adultas y prepúberes que alcanzaban una talla $>3 \mathrm{~mm}$ el diámetro del ovocito no aumentaba significativamente. Por otra parte, en ovejas de pelo adultas existe correlación positiva entre el estatus ovárico previo a un tratamiento de estímulo superovulatorio y su nivel de respuesta (Domínguez Rebolledo et al., 2017).

Al contrario de lo que se obtuvo en este trabajo y de lo que la literatura reporta, en un estudio realizado por O'Brien, Catt, Ireland, Maxwell y Evans (1997) no encontraron diferencias en ovejas prepúberes y adultas de la raza Merino con ovocitos provenientes de ovarios de matadero obtenidos por aspiración con jeringa, madurados y fertilizados in vitro. Esto coincide con el estudio de Revel, Mermillod, Peynot, Renard y Heyman (1995) en terneras de tres meses (no tratadas y tratadas con FSH exógena) comparadas con vacas adultas. Sin embargo, los mismos autores respectivamente, tuvieron diferencias $(P<0.001)$ hasta la etapa de blastocisto, con 15.4 y $34.1 \%$ para ovejas prepúberes y adultas, respectivamente; para terneras con 9.1 y $11.1 \%$ (no tratadas y tratadas con FSH) y para vacas adultas arriba de $20 \%$ de desarrollo hasta blastocisto, respectivamente. Se ha demostrado que los ovocitos de ovejas prepúberes y adultas tienen una capacidad diferente para el desarrollo in vitro; sin embargo, una vez que se ha logrado el desarrollo hasta la etapa de blastocisto el desarrollo in vivo parece ser similar para ambas. Cabe mencionar que en este trabajo los ovocitos de prepúberes no alcanzaron la etapa de blastocisto. 
Se logró sistematizar la técnica de LOPU e implementar un protocolo de fertilización in vitro a partir de los ovocitos recuperados y fertilizados. La edad reproductiva influye sobre el desarrollo de los ovocitos fertilizados in vitro.

\section{Agradecimientos}

Los autores desean agradecer el financiamiento de este trabajo a través del Proyecto 107996 FOMIXCONACYT-Gobierno del estado de Yucatán.

- $\quad$ Alberio, R., Olivera, J., Roche, A., Alabart, J., \& Folch, J. (2002). Performance of a modified ovum pick-up system using three different FSH stimulation protocols in ewes. Small Ruminant Research, 46(2-3), 81-87.

- Baldassarre, H. (2007). Aplicaciones prácticas de la producción de embriones in vitro en la especie caprina. Revista Brasileira de Reprodução Animal, 31 (2), 261-267.

- Baldassarre, H., Wang, B., Pierson, J., Neveu, N., Sneek, L., Lapointe, J., ... Karatzas, C. N. (2004). Prepubertal propagation of transgenic cloned goats by laparoscopic ovum pick-up and in vitro embryo production. Cloning and Stem Cells, 6(1), 25-29. doi: 10.1089/15362300460743808

- Brackett, B. G., Bousquet, D., Boice, M. L., Donawick, W. J., Evans, J. F., \& Dressel, M. A. (1982). Normal development following in vitro fertilization in the cow. Biology of Reproduction, 27(1), 147-158. doi: 10.1095/biolreprod27.1.147

- Chang, M. C. (1959). Fertilization of rabbit ova in vitro. Nature, $184,466-467$.

- Cox, J. F., \& Alfaro, V. (2007). In vitro fertilization and development of OPU derived goat and sheep oocytes. Reproduction in Domestic Animals, 42(1), 83-87. doi: 10.1111/j.1439-0531.2006.00735.x

- Domínguez Rebolledo, A., Vargas Manzanero, G., Alcaraz Romero, A., Quintal Franco, J., Baeza Rodríguez, J., Rivera Lorca, J., \& Ramón Ugalde, J. (2017). Follicular population at the onset of a superovulatory treatment and ovarian response in hair ewes. Romanian Biotechnological Letters, 22 (2), 1242712431.

- Hammami, S. (2008). Producción de embriones ovinos in vitro con vistas a la selección genética (Tesis de maestría). Instituto Agronómico Mediterráneo de Zaragoza, Zaragoza.

- Instituto Nacional para el Federalismo y el Desarrollo Municipal \& Gobierno del Estado de Yucatán. (2005). Enciclopedia de los Municipios y Delegaciones de México. Estado de Yucatán [Página electrónica]. Recuperado de http://www.inafed. gob.mx/work/enciclopedia/EMM31yucatan/index.html

- Juárez-Pérez, A., Domínguez-Rebolledo, A., Pinzón-López, L., Aguilar-Urquizo, E., Rivera-Lorca, J., \& Ramón-Ugalde, J. (2018). Estacionalidad reproductiva en ovejas tropicales superovuladas. Agroproductividad, 11 (10), 133-135.

- Khodaei, M., Shahneh, A. Z., Daliri, M., Kohram, H., \& Gharagozlou, F. (2008). In vitro maturation of sheep oocytes in different concentrations of mare serum. African Journal of Biotechnology, 7(18), 3380-3382.

- Koeman, J., Keefer, C. L., Baldassarre, H., \& Downey, B. R. (2003). Developmental competence of prepubertal and adult goat oocytes cultured in semi-defined media following laparoscopic recovery. Theriogenology, 60(5), 879-889. doi: 10.1016/s0093-691x(03)00090-6

- Martino, A., Mogas, T., Palomo, M. J., \& Paramio, M. T. (1994). Meiotic competence of prepubertal goat oocytes. Theriogenology, 41 (4), 969-980.

- O'Brien, J. K., Catt, S. L., Ireland, K. A., Maxwell, W. M., \& Evans, G. (1997). In vitro and in vivo developmental capaclty of oocytes from prepubertal and adult sheep. Theriogenology, 47(7), 1433-1443. doi: 10.1016/\$0093-691X(97)00134-9

- Palma, G. (2008). Producción in vitro de embriones. En Biotecnología de la reproducción (cap. 16, pp. 3133-3175).

- Pierson, J., Wang, B., Neveu, N., Sneek, L., Côté, F., Karatzas, C. N., \& Baldassarre, H. (2004). Effects of repetition, interval between treatments and season on the results from laparoscopic ovum pick-up in goats. Reproduction Fertility and Development, 16(8), 795-799. doi: 10.1071/rd04066

- Ramón-Ugalde, J. P., Folch, J., Cocero, M. J., Piña-Aguilar, R. E., \& Alabart, J. L. (2008). Embryo recovery from the oviduct in superovulated ewes: a method to improve MOET systems. Czech Journal of Animal Science, 53(4), 145-151.

- $\quad$ Revel, F., Mermillod, P., Peynot, N., Renard, J. P., \& Heyman, Y. (1995). Low developmental capacity of in vitro matured and fertilized oocytes from calves compared with that of cows. Journal of Reproduction and Fertility, 103(1), 115-120. doi: 10.1530/jrf.0.1030115

- Romaguera, R., Chacaltana, A., Fonseca, C., Anguita, B., 
Catalá, M., Casanovas, A., ...Paramio, M. T. (2007). Utilización de la LOPU en caprino: Valores foliculares y ovocitarios. ITEA, Extra 28(Tomo 1), 33-35.

- $\quad$ Shirazi, A., Shams-Esfandabadi, N. S., \& Hosseini, S. M. (2005). A comparison of two recovery methods of ovine oocytes for in vitro maturation. Small Ruminant Research, 58(3), 283-286. doi: 10.1016/j.smallrumres.2004.11.002

- Thibier, M. (1990). New technologies in cattle reproduction. Proceedings of the Regional Seminar held by the International Foundation for Science (IFS), Niamey, Niger (pp. 247-262).

- Tibary, A., Anouassi, A., \& Khatir, H. (2005). Update on reproductive biotechnologies in small ruminants and camelids. Theriogenology, 64(3), 618-638. doi: 10.1016/j. theriogenology.2005.05.016 